- of the Energy and Water appropriations bill worries science lobbyists for at least three reasons: the bill is clearly short of money, there is pressure to pass it quickly, and, most importantly, the administration has decided not to veto it.

Domenici would like to sit on the bill until after the August recess, in the hope

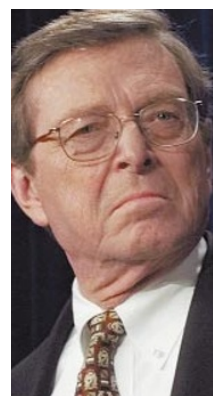
that it could share in the extra money that Congress and the administration are expected to find in September. But the Congressional leadership wants the Energy and Water bill passed quickly.

Mike Lubell, head of government affairs at Domenici: trying the American Physical to hold out for Society, predicts that extra money. the House and the Senate will split their differences without providing any extra money - leaving most programmes in the Office of Science facing modest but painful cuts.

Scientific societies are trying to prevent this. But the DoE's science programmes are vulnerable following its security problems with nuclear weapons and fierce clashes between Congressional leaders and its secretary, Bill Richardson.

The Senate has proposed a $\$ 2.7$ billion increase for the NIH, and it is thought that, after late budget negotiations, this is what it will get.

\title{
UK space strategy slammed as lacking funds and vision
}

\section{Natasha Loder, London}

Britain's traditional reluctance to make the same political commitment to space-based activity as its main economic competitors, which has been long criticized by the space community, has now come under strong attack from a cross-party group of Members of Parliament (MPs).

The House of Commons trade and industry select committee has been assessing space policy since last November. In its report, published last week, it says Britain's space strategy is limited in ambition, lacks leadership and is in urgent need of more money - and a radical rethink about how it is spent.

Much of the report focuses on the activities of the British National Space Centre (BNSC), the interdepartmental body set up in 1985 to coordinate the activities of the different parts of government interested in space.

The BNSC is an improvement over previous "ramshackle arrangements" and is successful at a European level, says the MPs' report. But the committee of MPs had received persistent complaints that the agency was failing to coordinate space activities because individual government departments wanted to keep control of their contributions.

The MPs now say the agency should be more proactive, that its role and organiza-

\section{Cluster leaves the ground — at last}

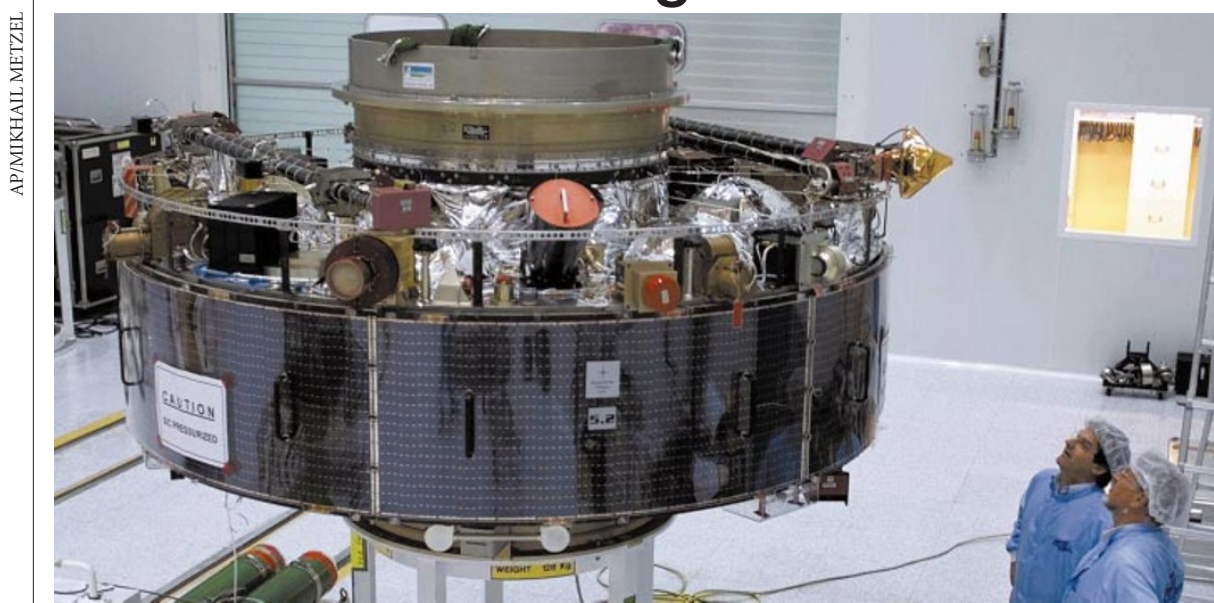

In waiting: French engineers inspect one of the Cluster satellites prior to its launch last Sunday.

After a nerve-wracking 24-hour delay, scientists are celebrating the successful launch of two of the four Cluster II satellites that will fly in formation around the Earth, sending back data on the weather in space. They were launched on Sunday at Baikonur Cosmodrome in Kazakhstan, after a last- minute hitch forced take-off to be postponed. The second pair of satellites will be launched on 9 August. Later this year scientists should start gathering data from the satellites on the structure of the Earth's magnetic field and the flow of charged particles trapped within it.

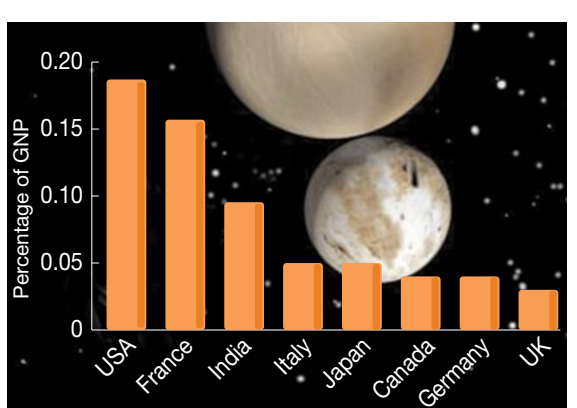

Lagging behind: latest figures put Britain's space spending at the bottom of the world league.

tion should be radically reviewed, and that it should produce annual reports. Also, thought must be given to whether it - or its successor - should have its own budget. Without this, say the MPs, the BNSC's "hands have been tied".

Ian Halliday, chief executive of the Particle Physics and Astronomy Research Council (PPARC), one of the agency's partners, says the BNSC's performance is "effective but not inspirational". This view is shared by Halliday's predecessor Ken Pounds, head of astronomy at Leicester University. Pounds says that for the past 15 years, Britain's attitude to space has been "far too cautious and conservative".

Halliday is also critical of how little money is spent on space science: $\mathfrak{1} 30$ million of PPARC's contribution to the BNSC goes on membership of the European Space Agency (ESA), and the rest is spent on instruments. Halliday describes ESA membership as comparable to belonging to a golf club while being able to afford only half a set of clubs.

Evidence presented to the select committee shows that Britain's public investment in space $\mathrm{R} \& \mathrm{D}$ is low in absolute and relative terms (see figure). The United Kingdom Industrial Space Committee — the British space industry's trade association - told MPs that "all the main space nations have increased their investment in space in recent years, whereas UK investment has at best remained static".

Although the MPs questioned the proportion of national spending on space compared with contributions to ESA, they also warned strongly against cutting ESA funding. They said this would seriously damage the UK space industry - about $80 \%$ of PPARC's contribution to ESA returns to British industry in the form of contracts.

But the MPs do not see greater collaboration with ESA as the best way forward. If the UK space budget were increased, they say, close consideration should be given to whether Britain would do better through bilateral arrangements with NASA, Japan, France, Germany or Sweden. 